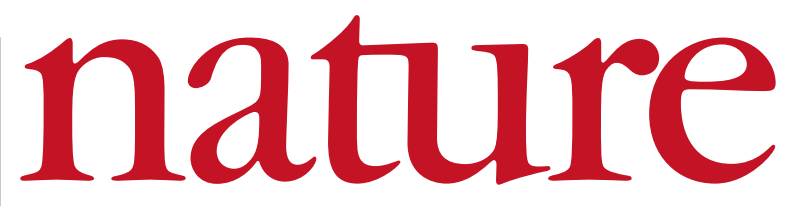

9 September 2004 Volume 431 Issue no 7005

\title{
Experiments in publishing
}

Nature's web forum on access to the primary literature has highlighted the risks, as well as the attractions, in enforcing availability without charge to readers.

"O ur idea - a rabbit out of the hat — of institutional repositories, will make the university library system sit up and listen." The rabbit described by Ian Gibson, who is a UK member of parliament, is a recommendation that funding bodies require scientists to make their articles more accessible by publishing free copies on their institutions' websites. It came from the House of Commons Science and Technology Committee in July, after a five-month inquiry into journal pricing, chaired by Gibson.

The US National Institutes of Health (NIH) now seeks to do likewise. It plans to ask researchers to copy final versions of their manuscripts onto the US National Library of Medicine's freely accessible PubMed Central repository six months after publication (see page 115). Those who are concerned about such matters have about two months in which to comment (see http://grants1.nih.gov/grants/ guide/notice-files/NOT-OD-04-064.html).

But such grand schemes merit serious reality checks. The impact of the NIH plan on the viability of journals and on non-profit learned societies is potentially serious, and questions as to how it might affect the various sorts of journals have been insufficiently explored.

Over the past months, dozens of scientists and publishers have given their views on open access in a web forum at www.nature.com/ nature/focus/accessdebate. One conclusion of the forum, which wraps up this week, is that societies and publishers must remain financially healthy if they are to be able to maintain the quality of information, launch new journals and innovate electronically.

Contributions also indicate that one-size-fits-all solutions are illsuited to the huge range of journals and business models, from those with low operating costs, low rejection rates and low added value to more selective journals with high costs and significant added value. Is six months too short for some to sustain subscriber revenues?
The forum reveals that many scientific publishers, in particular learned societies, are already experimenting with ways of increasing access. Some give authors the option of paying for their own articles to be made open access. Many already make articles available from their own websites without charge after a delay. Given the latter, might it not be more sensible to encourage access to free material on publishers' sites, for example, instead of creating a parallel universe of papers on a single US-government-sponsored repository?

Some open-access advocates see open-access archiving as a step that would eventually oblige all journals to adopt a single business model of 'author-pays'. In this model, instead of covering the costs of publishing primary papers from subscriptions paid by readers, costs are met by charging fees to authors, their institutions or sponsors.

Visionaries predict that free institutional archives will cause libraries to cancel subscriptions, cutting journals' revenues and forcing them to turn to either author-pays or other open-access models, or downsize to become no-frills providers of peer-review services, or both. The author-pays model is being explored by open-access publishers such as the Public Library of Science and BioMed Central, but neither has yet demonstrated that it can break even, let alone that the model is sustainable for the entire literature.

Nature, founded on the traditional publishing model, welcomes alternative models that deliver enhanced access, provided that they also foster added editorial and publishing value. Its publishers are experimenting with new publishing models. The Nature forum indicates that the viability of new models remains far from established.

For politicians or state institutions in effect to support one business model would be risky. Diverse approaches and competition are usually preferable, particularly if investment and deployment of technological and other innovations are to be encouraged.

\section{Helping depressed children}

The FDA should improve public information and work to create a publicly accessible clinical-trials database.

T he US Food and Drug Administration (FDA) will meet next week to consider how to calm the firestorm over the use of antidepressant medications in children (see page 122). It is now armed with much more material than it had at its last meeting on selective serotonin reuptake inhibitors (SSRIs) in February. None of these data have altered the conclusions drawn by FDA epidemiologist Andrew Mosholder ahead of the February meeting, however. As a class, SSRIs are associated with an increased risk of suicidal thoughts and behaviours in young people.

The FDA is reluctant to discourage the use of SSRIs, because there are few good treatments for childhood depression, which can by itself lead to suicide. But there is little to suggest that children are better off on the drugs than not. Only one of the drugs, Prozac, has consistently improved childhood depression more than placebo treatment.

The FDA needs to make a statement reflecting these facts, to counteract the long holiday that drug companies have enjoyed. Crucial data about the lack of efficacy and side effects of SSRIs in children have not been clearly described or even published in medical journals. Without access to the full findings, US doctors wrote 10.8 million prescriptions for the drugs for children and adolescents in 2002. The FDA is responsible for stopping this widespread 'off-label' use.

Drug companies are now allowed to market their products directly to US consumers. But they do not reveal all the information they have about these drugs to potential patients. A new method of disclosure must be created that is as understandable as the TV and magazine ads that spread rosy messages about today's blockbuster drugs.

The drug companies have begun to respond to such demands by posting information about approved drugs on their websites. But the industry's reputation is so tarnished that this is unlikely to be sufficient. The FDA and other agencies should collaborate to develop a clinicaltrials database containing information on every clinical trial sponsored by a drug company. It should include all the clinical results from drugs that have been approved for any indication. Such a move would go some way towards restoring the FDA's dented credibility. 